\title{
Treatment of Chronic Urticaria
}

\author{
Ružica Jurakić Tončić, Jasna Lipozenčić, Branka Marinović \\ University Department of Dermatology and Venereology, Zagreb University Hospital \\ Center and School of Medicine, Zagreb, Croatia
}

\author{
Corresponding author: \\ Professor Jasna Lipozenčić, MD, PhD \\ University Department of Dermatology \\ and Venereology \\ Zagreb University Hospital Center and \\ School of Medicine \\ Šalata 4 \\ HR-10000 Zagreb \\ Croatia \\ jasna.lipozencic@zg.htnet.hr
}

Received: March 4, 2009

Accepted: May 12, 2009

\begin{abstract}
SUMMARY Urticaria is a disorder characterized by rapid onset of localized swelling of the skin or mucosa, called wheals or urtica. According to frequency and duration, urticaria can be divided into acute and chronic type. Chronic urticaria is any type of urticaria occurring every day or twice per week, lasting longer than 6 weeks. Chronic urticaria is a common disorder and estimated prevalence is $1 \%$ of the population. Also, it is not rare in childhood.

The pathogenesis of chronic urticaria has not yet been completely understood. Chronic urticaria is a heterogeneous group of disorders, and according to the etiology and cause, several groups of chronic urticaria are distinguished, i.e. autoimmune, pseudoallergic, infection-related, physical urticaria, vasculitis urticaria and idiopathic urticaria. Treatment and management of chronic urticaria can be non-pharmacological and pharmacological, and sometimes it is not possible to control the disease with antihistamines only, which are considered to be the mainstay of treatment. In severe cases of chronic urticaria, especially if autoimmunity has been proven, several authors describe different modules of immunomodulation: cyclosporine, cyclophosphamide, mycophenolate-mofetil, omalizumab, plasmapheresis, systemic corticosteroids, and immunoglobulin therapy. This article primarily addresses the treatment of chronic idiopathic and autoimmune urticaria.
\end{abstract}

KEY WORDS: chronic urticaria, $\mathrm{H} 1$ antagonist, corticosteroids, autoimmune urticaria, chronic idiopathic urticaria, immunomodulators

\section{INTRODUCTION}

Urticaria is presented with short-lived swelling of the skin and mucosa due to transient leakage of plasma from small blood vessels into the surrounding tissue (1). Wheals or hives are superficial swelling of the dermis and are itchy. Any pattern of recurrent urticaria occurring twice weekly for
6 weeks is called chronic urticaria (1). There are no reliable data on the prevalence of chronic urticaria, but it is estimated at $1 \%(2)$. In some cases, there is involvement of deep dermis and subcutaneous tissue and it is presented as angioedema and can affect both the skin and mucosa $(3,4)$. 
Angioedema may be rather painful than itchy, and can coexist with wheals, however, wheals and angioedema can appear alone (1). The diagnosis of chronic urticaria is made on the basis of clinical appearance, detailed history data on the onset and duration of individual wheals, and also exclusion of some infective agents and systemic diseases such as thyroid gland disease and some other autoimmune disorders. Chronic urticaria is a heterogeneous disorder that can be divided into autoimmune, pseudoallergic, infection-related, physical, vasculitis and idiopathic urticaria (1). This article addresses autoimmune and idiopathic chronic urticaria, which pose a therapeutic problem.

The pathogenesis of chronic urticaria is still poorly understood. The term "chronic urticaria" makes no assumption about its case, but it is sometimes used closely to term "chronic idiopathic urticaria" (CIU). It is not justified because a large proportion of CIU can be ascribed to autoimmunity (1). About $50 \%$ of cases remain unexplained after evaluation for autoimmunity (1). CIU can be a very disabling condition and it can severely interfere with daily activities, quality of life and sleep. CIU is a common skin condition that affects $0.1 \%-0.3 \%$ of the population in the USA and Europe and accounts for nearly $75 \%$ of all chronic urticaria cases (5).

In pediatric population, causative agents are identified in about $20 \%$ of cases (3). About $5 \%$ $10 \%$ are caused by physical factors; other triggers are infections (mostly viral), foods, additives, aeroallergens and drugs (3). CIU is defined by exclusion of other possible causative agents. About one third of children with chronic urticaria have circulation autoantibody against high-affinity IgE receptor or against IgE. It is not known why these antibodies are produced or how they alter the course of the disease.

Besides histamine, other mediators such as prostaglandins, leukotriens and kinins are also involved, and it is often quite difficult to treat urticaria with antihistamines alone (4). In 2006, a review article on EEACI/GA²LEN/EDF guideline for definition, classification and diagnosis of urticaria was published by Zuberbier et al. (6). According to this guideline, the classification of urticaria is made on the basis of its duration, frequency and causes. The diagnosis is based on detailed patient personal and family history. The authors recommend the following questions to ask: 1) time at onset of disease, 2) frequency and duration of wheals, 3) diurnal variation, 4) shape, size and distribution of wheals, 5) associated angioedema, 6) associated symptoms of lesion, 7) family history regard- ing urticaria and atopy, 8) previous or current allergies, infections, internal diseases, 9) induction by physical agents or exercise, 10) use of drugs, 11) food, 12) smoking habits, 13) type of work, 14) hobbies, 15) occurrence on weekends, holidays and foreign travel, 16) surgical implants, 17) reaction to insects, 18) connection to menstrual cycle, 19) stress, and 20) quality of life. Thorough history should be followed by physical examination and testing for dermographism $(2,6)$.

Different types of urticaria require different diagnostic work-up algorithms. Once the pseudoallergic reactions and underlying diseases have been excluded, the likelihood of finding the cause is very low. It is necessary to obtain very detailed history data on the medications taken per need, which are usually forgotten by the patient him/ herself, e.g., for headache, since pseudoallergic reactions to nonsteroidal antiinflammatory drugs (NSAID) are not rare. When analyzing food as the possible cause, the main problem is identification of additives and preservatives, which should be excluded from dietary habits because certain foods can cause pseudoallergic reactions, e.g., reaction to tartrazine can be one of the manifestations of hypersensitivity to acetylsalicylic acid. Urticaria and angioedema can appear as a symptom of systemic disease (collagenopathies, malignancies, hemolytic diseases, endocrinopathies, celiac disease), or can be congenital (hereditary angioedema) (3). There is an increasing incidence of thyroid disease in patients with urticaria (3). IgE independent reactions are common in adult patients with chronic urticaria.

Almost every malignancy has been reported to be associated with urticaria. It is recommended to exclude malignancies, especially in elderly patients or in patients with symptoms of loosing weight and other nonspecific symptoms. A variety of hematopoietic malignancies and malignancies of gastrointestinal tract are probably most important to exclude. It is recommended to perform fecal occult blood test, Pap smear, screening for prostate and pelvic examination. From our experience, it is reasonable to start with serum markers for malignancies.

Some reports show connection with Helicobacter $(H$.) pylori infections; screening revealed a higher incidence of asymptomatic $H$. pylori infections in a group of patients with chronic urticaria. Also, stool can be tested for Candida albicans and other parasitic infestations. Anyhow, a very small proportion of chronic urticaria cases are infectionrelated (1). 
The only test for autoantibodies against $\lg \mathrm{E}$ receptor available is autologous serum skin test, which shows the presence of serum histamine releasing factors of any type, not just antibodies (6). Another useful method is evaluation of histamine release from basophils, however, it is not performed routinely (6). Besides autoimmune pathogenesis mediated by functionally active autoantibodies to the high affinity $\lg E$ receptor or to $\lg E$, which are able to induce histamine release from basophils and mast cells and are found in only $50 \%$ of patients with chronic urticaria, a few more pathomechanisms must obviously be involved.

It has been recently published that an additional pathogenetic mechanism may be involved; there is activation of coagulation cascade and production of thrombin, a serine protease involved in edema formation due to the increase in vascular permeability, mast cell activation and degranulation, and production of anaphylatoxin C5a $(7,8)$.

It is necessary to identify the trigger; trigger removal is the only causal treatment and also identification of contributing agents, for example, use of NSAIDs causes worsening of chronic urticaria.

It is also important to note that extensive laboratory tests are not necessary in all cases; it depends on history data. Chronic urticaria can persist for many years, but resolves spontaneously in $30 \%-55 \%$ of patients (4).

\section{MANAGEMENT OF CHRONIC URTICARIA}

The EEACI/GA²LEN/EDF guideline for the management of urticaria is a consensus reached during panel discussion at the Second International Consensus Meeting on Urticaria, Urticaria 2004, a joint initiative of the EAACI Dermatology Section and GA'LEN (9). According to this guideline, management is divided into three basic approaches. First approach is avoidance, elimination or treatment of eliciting stimulus or cause. This is the best way since identification of the cause allows for successful treatment; however, it may not be possible in all cases. It includes elimination of medicaments, physical stimuli, eradication of infectious agents and treatment of inflammatory processes, and also removal of $\mathrm{Fc} \varepsilon \mathrm{RI}$ autoantibodies. It is applicable in patients with some lgE-mediated or physical urticaria. Second approach is inhibition of mast cell mediator release and nowadays the most commonly used drugs inhibiting mast cell release are corticosteroids. Other drugs with inhibiting activity on mast cells are, for example, cyclosporin A and PUVA therapy. Third approach is therapy to target organ, e.g., antihistamines.

Many pharmacological and non-pharmacological treatments are available. None of them is universal and treatment should be tailored individually. The mainstay of treatment for all types of urticaria are antihistamine agents and they are first-line therapy (1). Providing understandable and useful information is necessary, e.g., already mentioned avoidance of NSAIDs and use of acetaminophen when analgesics or antipyretics are required, because NSAIDs aggravate the symptoms of chronic urticaria (12). It is also recommended to avoid codeine and other opiates due to enhanced skin test for codeine in patients with chronic urticaria. Aggravation of chronic urticaria is usually seen during viral infection and it is often difficult to differentiate whether aggravation is due to the reaction to virus or due to the medication taken. It is also recommended to avoid dietary pseudoallergens such as food additives and colors, preservatives and natural salicylates $(1,2,12-14)$.

\section{ANTIHISTAMINE AGENTS}

Antihistamines are considered as first-line therapy (15). Antihistamines reduce itch, whealing, or both $(1,16)$. Antihistamines not only relieve itching, but they also reduce the number, size and duration of urticarial lesions (16). Histamine is a mediator of itch, but also few other mediators are involved such as mast cell tryptase and substance P (17).

Antihistamines are traditionally divided into groups. First generation of antihistamines is represented by promethazine, hydroxyzine, chlorpheniramine, deschlorpheniramine, ketotifen and cyproheptadine, and these drugs have sedative effect. Cetirizine, loratadine, mizolastine, ebastine and terfenadine are antihistamines of second generation. The new generation of antihistamines is represented by fexofenadine, desloratadine and levocetirizine.

All patients should be offered at least 2 nonsedating or minimally sedating agents. Antihistamines should be taken daily, not per need. Histamine $\mathrm{H} 1$ receptor antagonists are the only drugs licensed for use in urticaria $(1,18,19)$. Newer generation antihistamines are effective and safe at higher doses, although higher rates of sedation have been demonstrated with higher doses of some agents, e.g., cetirizine $(18,19)$.

Good therapeutic response has been reported in $55 \%$ of patients with CIU (20). In $94 \%$ of patients antihistamines are effective in itch relief, so 
the first therapeutic choice should always be an antihistamine agent (21).

First generation antihistamines are the sedating ones. Although newer antihistamines are considered as non-sedating when administered in higher doses, some sedation and drowsiness can be experienced, especially in first months of therapy, slightly more when levocetirizine is used when compared to desloratadine $(22,23)$. Sedation may reduce discomfort, especially at bed time, but sedation is potentially dangerous during the day since it impairs driving performance and decreases work capability (1).

Some authors suggest the use of non-sedating second generation antihistamines in the morning and the sedating ones in the evening (24). Sedating antihistamines have more adverse effects and should be reserved for patients who do not respond to the low-sedating group of antihistamines (1). Second generation antihistamines do not induce sedation, with the exception of cetirizine $(19,25)$.

The risk of ventricular arrhythmias associated with non-sedating antihistamine drugs is very low. According to the authors, the use of non-sedating antihistamine drugs increases the risk of ventricular arrhythmia by factor four in the general population, requiring 5300 person/year of use for one case to occur $(26,27)$.

According to recent literature data, it is better to treat chronic urticaria daily, by continuing therapy, than to treat it only when the symptoms return (28).

Although $\mathrm{H} 1$ receptor-mediated reactions are responsible for vasoactivity, vasopermeability and itching, it is clinically observed that the addition of $\mathrm{H} 2$ receptor antihistamine to $\mathrm{H} 1$ receptor antihistamine may provide better effect. According to literature data, $\mathrm{H} 2$ receptor blocker have potential effects with $\mathrm{H} 1$ blocker in suppressing histamineinduced wheal (29).

Second-generation histamine $\mathrm{H} 1$ receptor antagonists have been developed to provide efficacious treatment of allergic rhinitis and CIU, combined with decreasing adverse effects which were associated with first generation agents. Second generation antihistamines are highly selective for $\mathrm{H}-1$ receptor. They have shown limited effects on the central nervous system, with almost no significant drug-drug interactions noted in clinical studies. No major cytochrome P450 inhibition has been reported with desloratadine, fexofenadine and levocetirizine, and the bioavailability of deslo- ratadine is minimally affected by drugs interfering with transporter molecules. Of second generation antihistamines, desloratadine has the greatest binding affinity for $\mathrm{H}-1$ receptor (30).

Fexofenadine (Telfast ${ }^{\circledR}$ ) is a non-sedating antihistamine, which also shows an anti-inflammatory action (31). Fexofenadine is an active metabolite of terfenadine. It does not affect driving or psychomotor performance and has been shown to improve quality of life in patients with seasonal allergic rhinitis and chronic urticaria (33). It has a high margin of safety and is also well tolerated in patients with renal or hepatic impairment, in children and the elderly. No clinically significant drug interactions have been identified. It is not associated with cardiotoxicity $(33,34)$. There is a single case report with QT lengthening and life threatening arrhythmia in a patient with pre-existing heart disease (35). Unlike some other antihistamines such as loratidine or cetirizine, fexofenadine is truly non-sedating and shows no dose-related increase in sedation, even at high doses. It is formulated as the hydrochloride salt. The recommended dose of fexofenadine HC1 is $120 \mathrm{mg}$ daily for seasonal allergic rhinitis (either as $120 \mathrm{mg}$ once daily or $60 \mathrm{mg}$ twice daily) and $180 \mathrm{mg}$ once daily for CIU $(33,36)$.

According to data from a recent study, a significant decrease was demonstrated in the expression of ELAM-1, VCAM-1 and tryptase, and these preliminary data show a trend towards a decrease in the expression of these molecules after treatment, suggesting an anti-inflammatory activity of fexofenadine (31). The most common adverse event is headache (34).No effect on psychomotor abilities or cardiac arrhythmia were observed.

A new oral suspension formulation of fexofenadine has been developed for the indication of seasonal allergic rhinitis symptoms in children aged 2-11 years and for uncomplicated skin manifestations of CIU in children aged 6 months to 11 years. Clinical studies have shown the oral suspension to have both bioequivalence with the $30-\mathrm{mg}$ tablet formulation and a favorable safety and tolerability profile (37).

When compared to montelukast, fexofenadine suppressed the allergen-induced wheal-and-flare response to a significantly greater extent, and had a significantly faster onset of action (38). When compared to desloratadine, fexofenadine has a faster onset of flare suppression than desloratadine (1 hour vs. 5 hours) and an as rapid onset of wheal suppression. Fexofenadine $\mathrm{HCl}, 180 \mathrm{mg}$, 
was superior to desloratadine, $5 \mathrm{mg}$, in histamineinduced wheal-and-flare suppression, suggesting an increased in vivo H1-receptor antagonist potency of fexofenadine versus desloratadine (39).

Desloratadine $\left(\right.$ Clarinex $^{\circledR}$, Neoclarityn ${ }^{\circledR}$, Aerius $^{\circledR}$, Azomyr $^{\circledR}$, Opulis $^{\circledR}$ ) is a rapid-acting, once-daily, non-sedating selective H1-receptor antagonist/ inverse receptor agonist with proven clinical efficacy in patients with CIU (40). It has 10 - to 20 -fold in vivo $\mathrm{H} 1$ receptor-binding affinity of loratadine, and 52- to 194-fold $\mathrm{H} 1$ receptor-binding affinity of cetirizine, ebastine, loratadine and fexofenadine. It has linear pharmacokinetics after oral administration. There are no drug and food interactions, and it does not impair the psychomotor ability (40-42). It is also important to note its anti-inflammatory effects independent of $\mathrm{H} 1$-receptor antagonism. According to the authors, once-daily desloratadine $5 \mathrm{mg}$ is well tolerated and superior to placebo in reducing pruritus and wheals associated with CIU. It provides rapid and sustained relief of CIU symptoms as early as after the first dose and maintains this effect until the end of 6-week treatment period (43). Desloratadine is an active metabolite of loratadine, and is safe and well tolerated. The most common adverse event is headache, with no relevant changes recorded in ECG and laboratory tests (44). In 2004, the ARIA/EAACI report appeared assessing the efficacy, safety and pharmacology of desloratadine (45). This document outlined the need for determining the clinical efficacy of antihistamines in terms of disease and symptom control rather than in simulated models. It is also noted that there is no third generation of antihistamines. Based on this systematic review, the authors conclude that the efficacy, safety and pharmacology meet the ARIA/EACCI criteria for antihistamines (45). Desloratadine has an inhibitory effect on IL-3, IL-6, IL-8, TNF- $\alpha$ and GM-CSF release from mast cells and basophils in humans (46). Results of in vitro and in vivo studies have suggested that desloratadine has anti-allergic effects that are unrelated to its ability to antagonize the effects of histamine. Desloratadine inhibits the expression of cell adhesion molecules, inhibits the generation and release of inflammatory mediators and cytokines, and attenuates eosinophil chemotaxis, adhesion and superoxide generation $(47,48)$.

The safety profile of desloratadine is excellent $(48,49)$. So far, no effect on QRS and QTc intervals has been observed and it does not cause arrhythmias. Desloratadine is not associated with any significant changes in gastrointestinal function. In clinical studies, oral desloratadine is rapidly absorbed and bioavailability is not affected by ingestion of food or grapefruit juice. The half-life of desloratadine in humans is $27 \mathrm{~h}$; the linear kinetic profile is unaltered by race or sex. Desloratadine is not a substrate for $\mathrm{P}$-glycoprotein or organic anion transport polypeptide and the drug does not appear to be metabolized to a significant extent by the cytochrome P450 CYP3A4 pathway. It therefore may be safely administered with ketoconazole, erythromycin, fluoxetine, or azithromycin (48).

Some recent findings suggest the involvement of oxidative stress in the pathogenesis of CIU. There are some preliminary results that desloratadine exerts antioxidant effects in vivo (51). It has been shown in multiple studies to be safe and effective in relieving the symptoms of allergic rhinitis and CIU in adults and adolescents, but also in children aged 2-11 years with allergic rhinitis or CIU (52). When compared to levocetirizine, levocetirizine $5 \mathrm{mg}$ was significantly more efficacious than desloratadine $5 \mathrm{mg}$ in the treatment of CIU symptoms $(53,54)$. Desloratadine can be combined with dapsone in the treatment of chronic urticaria (55). One group of authors assessed the efficacy and safety of desloratadine combined with dipyridamole in the treatment of chronic urticaria and found significant difference when compared with a group treated with desloratadine only (56).

Recently, antileukotriene receptors have been used in patients with CIU, either administered as monotherapy or combined with $\mathrm{H} 1$-receptor antagonists. According to the authors, patients were treated with $5 \mathrm{mg}$ of desloratadine once daily, 10 mg of montelukast once daily, $5 \mathrm{mg}$ of desloratadine in the morning plus montelukast in the evening, and compared with placebo. According to study results, regular combined therapy with desloratadine plus montelukast did not seem to offer a substantial advantage with respect to desloratadine as monotherapy in patients affected by moderate CIU (57). Other authors found some benefit in the treatment of seasonal allergic rhinitis with the addition of antileukotriene antagonist to antihistamine therapy. This combination is believed to exert additional anti-inflammatory activity as provided by reduction of inflammatory infiltrate and cytokine levels. It is observed that cetirizine might exert more beneficial activity than desloratadine when added to montelukast (58).

Levocetirizine $\left(\mathbf{X y z a}^{\circledR}\right)$ is an R-enantiomer of cetirizine dihydrochloride. Levocetirizine has high bioavailability, high affinity for and occupancy of $\mathrm{H} 1$ receptor (30). It has shown rapid onset of 
action. Levocetirizine is safe and effective for the treatment of allergic rhinitis and CIU in adults and children with a minimal number of undesirable effects (59-63). Levocetirizine does not prolong the QT/QTc interval in healthy subjects, as demonstrated in thorough QT study $(30,64)$. It undergoes minimal hepatic metabolism, and is largely eliminated by urine, therefore, dose reduction is recommended in patients with renal impairment (4). Levocetirizine has several anti-inflammatory effects (65). It is indicated for PAR and CIU. Some antihistamines are capable of reducing levels of adhesion molecules in patients with chronic urticaria. Levocetirizine $5 \mathrm{mg}$ daily demonstrated a broad anti-inflammatory effect in patients with chronic urticaria. The significant decrease in serum levels of ELAM-1 and P-selectin might reflect the inhibitory activity on neutrophil rolling and extravasation towards inflamed skin $(65,66)$. It has recently been published that levocetirizine modulates lymphocyte activation in patients with allergic rhinitis. Study data showed reduced percentage of eosinophils and three subpopulations of activated T lymphocytes, CD4+CD29+, CD4+CD212+ and CD4+CD54+. Levocetirizine treatment also correlated with a significant increase in the percentage of CD4+CD25+ T cells. The ability of levocetirizine to reduce percentage representation of cell phenotypes known to contribute to inflammatory tissue damage (eosinophils, CD4+CD29+, CD4+CD212+, and CD4+CD54+) and expand the percentage of CD4+CD25+, which may include protective immunoregulatory (Treg) cells, indicates that the drug has a pharmacological potential beyond the immediate effects of $\mathrm{H} 1$ histaminereceptor inhibition $(67,68)$.

On comparison of levocetirizine $5 \mathrm{mg}$ and desloratadine $5 \mathrm{mg}$, levocetirizine $5 \mathrm{mg}$ was significantly more efficacious than desloratadine $5 \mathrm{mg}$ in the treatment of CIU symptoms $(53,54)$.

Recently, one case report appeared on fixed drug eruption to cetirizine with positive lesional patch tests to three piperazine derivatives. This is the first report of fixed drug eruption to cetirizine with positive patch testing for hydroxyzine, cetirizine and levocetirizine (69).

Ebastine is a second-generation antihistamine that is effective in the treatment of seasonal allergic rhinitis and PAR. It is available as regular tablet or as fast-solving tablet formulation which disintegrates in the mouth without drink, and also in combination with pseudoephedrine (70). According to the authors, ebastine in a dose of $10 \mathrm{mg}$ once daily improved symptoms to a significantly greater extent than placebo and to a similar extent as loratadine $10 \mathrm{mg}$ and cetirizine $10 \mathrm{mg}$ (both once daily), while ebastine $20 \mathrm{mg}$ proved to be more effective than these two comparator antihistamines. In addition, ebastine was significantly more effective than placebo in relieving the symptoms of CIU. Ebastine provides efficacy throughout the 24-h dosing interval with once daily administration and clinical benefit is seen from the first day of treatment. Small studies have found beneficial effects of ebastine in patients with other disorders, including cold urticaria, dermographic urticaria, atopic asthma, mosquito bites and in combination with pseudoephedrine for common cold $(70,71)$. Ebastine $20 \mathrm{mg} /$ day is indicated in patients with moderate and severe allergic symptoms. No cardiovascular effects of ebastine are described, although there is a pharmacokinetic interaction when ketoconazole or macrolides are co-administered (71). Ebastine does not affect psychomotor performance $(70,71)$. Furthermore, ebastine 5-10 $\mathrm{mg}$ and $2.5 \mathrm{mg}$ appears to be efficient and can be used safely in children 6-11 and 2-5 years of age, respectively (71). There is no need for dose correction in elderly patients, or in patients with renal or mild to moderate hepatic impairment (71). Ebastine appears to be a safe, effective and welltolerated second generation antihistamine in the treatment of allergic rhinitis and CIU $(70,71)$. However, there is one case report published in 2007 about ebastine induced hepatotoxity (72). Other authors report good safety profile of ebastine (7375).

In 2007, a comparative study on desloratadine $5 \mathrm{mg}$ vs. ebastine fast-dissolving tablet 20 mg investigated inhibition of cutaneous histamine reaction in healthy non-atopic adults. All adverse events were mild or moderate and most participants expressed preference of fast dissolving formulation (75).

Rupatadine (Rupafin ${ }^{\circledR}$, Rinialer $^{\circledR}$, Rupax $^{\circledR}$, Alergoliber $\left.^{\circledR}\right)$ is a newer dual inhibitor of histamine $\mathrm{H}(1)$ - and PAF (platelet-activating-factor)-receptors. It has been shown to be an effective and well-tolerated treatment for allergic rhinitis and CIU for patients aged over 12 years (76). Used once daily in a dose $10 \mathrm{mg}$ it has a fast onset of action with rapid symptom relief, and it also has an extended duration of clinical activity. According to the authors, rupatadine was shown to be at least as effective as drugs such as loratadine, cetirizine, desloratadine and ebastine in reducing allergic symptoms in adult/adolescent patients with seasonal, perennial or persistent allergic rhinitis 
and chronic urticaria. So far, no adverse cardiovascular effects where observed in preclinical or extensive clinical testing, or negative significant effects on cognition or psychomotor performance (including a practical driving study) (76-78). There is no drug interaction with azithromycin, fluoxetine and lorazepam, but it should not be administered with known CYP3A4 inhibitors (78).

\section{DOXEPINE}

Doxepine is a tricyclic antidepressant drug. In a dose of 25-75 mg/day it has been shown to be effective in the treatment of chronic urticaria, without significant adverse side effects. Doxepine has combined $\mathrm{H} 1, \mathrm{H} 2$ and muscarinic blocking activities, which may explain its clinical efficacy in the treatment of chronic urticaria (79). Treatment with doxepine is very useful when chronic urticaria is associated with depression or anxiety. The drug can be given in a dose of $25 \mathrm{mg}$ orally twice daily or as a single dose of $25 \mathrm{mg}$ at bedtime. It should not be co-administered with terfenadine or monoamine oxidase inhibitors $(79,80)$. It has been shown to be more effective and less sedating than diphenhydramine, and as effective as mequitazine in the treatment of CIU (80). Due to sedation, it should be given at bedtime.

\section{LEUKOTRIENE RECEPTOR ANTAGONISTS}

Cysteinyl leukotrienes (CysLTs) are potent proinflammatory mediators derived from arachidonic acid through the 5-lypoxigenase pathway. They exert important pharmacological effects by interaction with at least two different receptors, CysLT1 and CysLT2 $(1,81)$. By competitive binding to the CysLT1 receptor, leukotriene receptor antagonist drugs such as montelukast, zafirlukast and pranlukast block the effects of cysteinyl leukotrienes. Recently published studies and case reports have demonstrated beneficial effects of leukotriene receptor antagonist (LTRAs) on other diseases commonly associated with asthma, e.g., exercise induced asthma, rhinitis, chronic obstructive pulmonary disease, interstitial lung disease, chronic urticaria, atopic dermatitis, allergic fungal disease, nasal polyposis, and paranasal sinus disease (81). LTRAs are not licensed for urticaria. However, there are some reports and small studies about beneficial effects of this group of drugs in CIU management (82).

According to Wan, the combination of LTRAs and $\mathrm{H} 1$ receptor antagonist is promising for $\mathrm{CIU}$ treatment and is reasonably well tolerated by patients. Results of this study showed the combination of $\mathrm{H} 1$ - and $\mathrm{H} 2$-receptor antagonists to provide highest treatment efficacy by the measures used in this study (82). Still, results of conducted studies are mixed. Several authors describe beneficial effects, whereas other found no therapeutic impact of the addition of LTRAs. One study compared the treatment of $\mathrm{CIU}$ with desloratadine alone and with desloratadine plus montelukast. According to study data, the combination of desloratadine plus montelukast was found to improve the symptoms and patient quality of life significantly more than desloratadine alone, although it did not have a significant effect on the number of urticarial episodes $(57,83,84)$. Another comparative study of desloratadine alone, montelukast alone and a combination of these two drugs demonstrated desloratadine to be highly effective for the treatment of patients affected by CIU. In addition, the regular combined therapy with desloratadine plus montelukast did not seem to offer any substantial advantage over desloratadine monotherapy in patients with moderate CIU (57). In 2006, a review article appeared on montelukast; results of the studies analyzed were mixed and controversial. So far, no clear conclusion can be made and large controlled trials are lacking. However, it seems that LTRAs may prevent severe urticaria/angioedema exacerbations that follow the use of NSAIDs in some patients with chronic urticaria (86-88).

\section{ORAL CORTICOSTEROIDS}

The most frequently used drugs inhibiting mast cell mediator release are corticosteroids. In general, corticosteroids should be avoided in long term treatment because of serious adverse events, while in acute urticaria short-term usage can be very helpful in order to reach fast symptom control. A short tapering course of corticosteroids may be useful in antihistamine resistant $\mathrm{ClU}$, when rapid control is needed. Different schemes and dosages have been suggested in the literature, but it is common to start with prednisolone $40 \mathrm{mg} /$ day, reduced by 5 mg every 5 days $(1,4,89-91)$. It is usually recommended to continue with antihistamine therapy during this short course of antihistamines. Long term therapy should be avoided due to serious adverse events such as diabetes mellitus, hypertension, Cushing syndrome, osteoporosis, and others.

\section{PLASMAPHERESIS}

A group of patients with chronic idiopathic urticaria have circulating functional autoantibodies 
against the high affinity $\lg E$ receptor, or in some cases IgE antibodies. Whether autoantibodies cause chronic urticaria remains unknown, but intradermal injection of anti-FceR1 lgG in healthy volunteers has been shown to cause urticarial reaction. So, there is a concept of chronic urticaria as a disease caused by autoantibodies activating the normal function of mast cells. Autologous serum skin test has proved to be a useful screening test for autoimmune urticaria. Identification of patients with autoimmune urticaria is important because immunotherapy can be necessary and useful, using cyclosporine, intravenous immunoglobulin, or even plasmapheresis in severe cases of therapyresistant chronic urticaria (92). In 1992, in Lancet, a group of authors described plasmapheresis in the treatment of severe, unremitting chronic urticaria (93). In 2008, a group of authors published a case report of double-filtration plasmapheresis for resolution of refractory chronic urticaria. Doublefiltration plasmapheresis removes medium to large molecular substances such as IgG and IgE from circulation and therefore can be an effective treatment option (94). Plasmapheresis is described by several authors as an alternative option for severe chronic urticaria unresponsive to other treatments, but it is not very often done (95).

\section{INTRAVENOUS IMMUNOGLOBULINS}

Intravenous immunoglobulins (IVIG) are used in patients with severe disease unresponsive to conventional treatment. As mentioned above, autoimmune pathogenic mechanism is implicated in about one-third of patients with chronic urticaria and involves circulating functional autoantibodies to either the high affinity $\lg E$ receptor $(\lg G 1 / \lg G 3$ anti-FcERI) or to lgE, with histamine releasing activity. A group of authors has described 29 patients with the diagnosis of autoimmune chronic urticaria treated with IVIG. They used low dose of IVIG treatment every 4 weeks $(0.15 \mathrm{~g} / \mathrm{kg})$ for a minimum of 6 months and a maximum of 51 months. Twenty-six patients had improvement of symptoms and the need for oral antihistamine medication was decreased. Nineteen of 26 patients achieved complete remission of symptoms; 20 patients remained without symptoms for 12 months of active treatment; and six patients reported only mild complaints. The authors conclude that IVIG is an effective therapeutic option in patients suffering from severe chronic urticaria refractory to conventional treatment, in which autoimmune mechanism is involved. The efficacy persists for at least 12 months of treatment. However, the number of in- fusions needed to achieve clinical control greatly varied among patients (96). In another study, ten patients with positive circulating antiFcERI or anti$\mathrm{IgE}$ antibodies were given IVIG $2 \mathrm{~g} / \mathrm{kg}$ for 5 days and this therapy was efficient in nine patients and induced prolonged remission in three patients (97). One case report describes good result with low dose $(0.2 \mathrm{~g} / \mathrm{kg})$ over one day. However, the authors point out that the results can last shortly (98).

\section{SULFASALAZINE}

Sulfasalazine 500-4000 mg/day for the treatment of CIU has been reported in several articles. In 2006, a report appeared on 19 patients with antihistamine-unresponsive CIU treated with sulfasalazine between 2002 and 2005 (99); 74\% of patients experienced significant improvement, $21 \%$ reported minimal improvement but were not satisfied with their symptom relief, and $5 \%$ reported worsening of symptoms. All patients that required systemic steroids for symptom control were able to reduce or discontinue steroid use during sulfasalazine therapy. Adverse effects were reported in $37 \%$ patients and included nausea, headache, mild or transient leukopenia, and elevation of transaminases, and were thought to be caused by sulfasalazine. Sulfasalazine can be used in patients with CIU that do not respond to antihistamines; it is a steroid sparing drug $(4,99,100)$. There also are several case reports on successful sulfasalazine treatment of severe CIU associated with pressure urticaria and angioedema $(101,102)$.

\section{METHOTREXATE}

Two CIU patients successfully treated with methotrexate were described in 2001 (103). Seven patients with CIU treated with methotrexate 2.5 mg every 12 hours, two days a week for a 6-week period were reported in 2004 (104). Statistically significant improvement was observed in itching, presence of wheals and sleep quality. There was no statistical difference in the extension of lesions and presence of angioedema. Adverse effects were not significant. There are only several case reports, but the efficacy of methotrexate has not been proven in large controlled studies. There are few literature reports on pulmonary edema, sometimes even fatal, caused by methotrexate in low doses, and on pancytopenia that was observed with higher dose (106-108). The most important risk factor for methotrexate toxicity is impaired renal function. Pancytopenia can occur at any time during therapy with methotrexate. 


\section{MYCOPHENOLATE MOFETIL}

Mycophenolate mofetil (MMF) has been registered for prophylaxis of solid organ allograft rejection. MMF is now increasingly used for indications outside solid organ allograft rejection, often with limited supporting efficacy data. First line of treatment of patients with chronic urticaria are oral antihistamines and around $50 \%$ of patients respond well to antihistamines; others need a more aggressive approach, immunosuppressive therapy such as oral corticosteroids or cyclosporine. MMF may be a valuable and safe treatment for patients with chronic urticaria that do not respond to antihistamines and/or corticosteroids, and that require aggressive treatment. In 2006, nine patients were reported that received $1000 \mathrm{mg}$ twice daily MMF for twelve weeks. They showed significant decrease in the urticarial activity score. All patients were able to discontinue corticosteroids. There was also a decrease in antihistamine dose. Further controlled clinical studies are needed to determine the value of MMF in the treatment of severe CIU (110).

\section{CYCLOPHOSPHAMIDE}

Severe CIU can be treated with several immunomodulatory drugs. In recent literature, several case reports and small studies of cyclophosphamide (CTX) in the management of chronic urticaria treatment have been published. In one of these papers, one patient with severe CIU and positive autologous serum skin test had benefit from CTX 500-1500 mg every 2-4 weeks (111). The treatment started with the initial dose of $500 \mathrm{mg} \mathrm{CTX}$ intravenously, followed by increases of $100 \mathrm{mg}$ every 2 weeks, with the maximum dose reaching $1500 \mathrm{mg}$ once a month. Complete clinical remission was reached in 7 months and prednisone was discontinued. Repeat intracutaneous testing to autologous serum was negative, consistent with an abrogated autoantibody response (111). Another group of authors evaluated the efficacy of H1-antihistamine, corticosteroids and CTX in the treatment of chronic dermographic urticaria. One group of patients were treated with cetirizine hydrochloride $10 \mathrm{mg}$ per day orally, and the other group were treated with betamethasone $2 \mathrm{mg}$, CTX $50 \mathrm{mg}$ and cetirizine $10 \mathrm{mg}$ per day for a total period of 4 weeks. The majority of patients showed relapse within 3 days of treatment discontinuation. Study results showed that treatment supplementation with oral corticosteroids or CTX was more effective in symptom control than cetirizine alone. However, four-week supplementation was not adequate to prevent disease relapse upon drug discontinuation (112). Oral CTX has also been administered in case of cyclosporine- and steroid-resistant chronic urticaria with proven autoreactivity to autologous serum skin testing (113). The use of oral CTX has already been described in the treatment of Schnitzler's syndrome (114).

\section{CYCLOSPORINE}

Cyclosporine (Sandimun Neoral ${ }^{\circledR}$ ) (Csa) has been widely used in the prevention and treatment of organ transplant rejection and also in autoimmune diseases. Recently, Csa has been introduced in the treatment of severe 'idiopathic' urticaria. Several authors have described good results with this therapy $(105,115-117)$. A limited number of severe CIU patients treated with CsA have been reported in 1997 (116). It was open label study. In 2000, Grattan et al. treated 20 patients with CsA in a dose of $4 \mathrm{mg} / \mathrm{kg} /$ day for 4 weeks and compared it to placebo. All patients were given cetirizine 10 $\mathrm{mg} /$ day (117). They measured daily urticaria activity score, basophil histamine release and autologous serum skin test. Study results confirmed CsA efficacy and provided further evidence for the role of histamine-releasing autoantibodies in CIU (117).

According to Vena et al., CsA was given in the initial dose of $5 \mathrm{mg} / \mathrm{kg} /$ day and progressively reduced to $3 \mathrm{mg} / \mathrm{kg} / \mathrm{day}$. After a week of run-in period with cetirizine $10 \mathrm{mg}$, patients were given CsA for 8 or 16 weeks. Adverse events were recorded in six patients and included elevated serum creatinine. The patient quality of life was improved $(118,119)$. Patients with severe disease unresponsive to antihistamines and showing a positive autologous serum skin test were treated with CsA 4 $\mathrm{mg} / \mathrm{kg} /$ day of CsA for 4 or 12 weeks. Prolonged use of this therapy for more than 1 month provided little benefit in terms of clinical improvement. In a double-blind study published in 2003, 40 adults were assigned randomly to receive CsA (5 mg/ $\mathrm{kg} /$ day for 8 weeks and then $4 \mathrm{mg} / \mathrm{kg} /$ day for 8 weeks) or cetirizine (10 mg/day) and then followed up for 9 months (120). After 2 weeks, the study was opened because 16 (40\%) patients had daily severe relapses requiring systemic steroid treatment. All of these patients had been receiving antihistamines and therefore were assigned to the CsA treatment regimen ( $5 \mathrm{mg} / \mathrm{kg} /$ day for 8 weeks and then $4 \mathrm{mg} / \mathrm{kg} /$ day for 8 weeks). Only two patients failed to complete the study because of severe symptoms occurring after 4 and 7 days of follow up and requiring long-term steroid treatment. 
After 9-month follow up, 16 patients were still in full remission. These results show the long-term efficacy and tolerability of CsA in patients with severe CIU unresponsive to conventional treatment (120). Toubi et al. report on prolonged cyclosporinA treatment for severe chronic urticaria (121).

Low-dose and short-term cyclosporine treatment was evaluated in patients with CIU (122). Cyclosporine in a dose of $2.5 \mathrm{mg} / \mathrm{kg} /$ day in patients with severe CIU is efficient and safe. Improved clinical efficacy and marked decreases in serum cytokine levels suggest that inhibition of cytokine generation is involved in the action of the drug in this clinical setting. After 4 weeks of CsA therapy, the mean IL-2R, TNF- $\alpha$ and IL-5 levels were significantly decreased.

CsA is a calcineurin inhibiting immunomodulatory drug (123), and it has been shown to inhibit histamine release probably by interfering with intracellular signaling following cross-linking of $\lg \mathrm{E}$ receptor.

Many cutaneous side effects of CsA have been described, e.g., hypertrichosis, gingival hyperplasia, sebaceous gland hyperplasia and viral skin infections. One case report describes cyclosporine-induced follicular eruption (125-128). Unfortunately, CsA also has some major side effects (including nephrotoxic ones). Reversible ascending motor neuropathy as a side effect of systemic treatment with cyclosporine for nodular prurigo has been described in literature (129). When side effects of CsA are compared to tacrolimus, hypertension, hypertrichosis and gingival hyperplasia were less pronounced with tacrolimus and elevated blood glucose level was observed in the CsA group (130).

\section{TACROLIMUS}

Cyclosporine and tacrolimus are calcineurin inhibiting immunosuppressant agents useful in the treatment of immune-mediated inflammatory dermatoses (123). Tacrolimus is a macrolide immunosuppressant drug isolated from Streptomyces tsukubaensis and is widely used in organ transplantation (131). Oral tacrolimus for chronic urticaria treatment has been studied in an open-label prospective study (132). Nineteen patients were treated with doses between 0.05 and $0.2 \mathrm{mg} / \mathrm{kg} /$ day divided into two daily doses for 12 weeks; $70 \%$ of patients showed clinical response to this treatment. It is important to monitor renal and liver function during therapy. Adverse events reported seem to be less pronounced or similar to those with cyclosporine $(3,130,132-134)$. There is a new, once-daily formulation registered as Advagraft for European Union (135).

\section{OMALIZUMAB}

Omalizumab is a recombinant humanized monoclonal antibody against immunoglobulin lgE, and acts as a neutralizing antibody by binding $\lg \mathrm{E}$ at the same site as the high-affinity receptor. Omalizumab is a monoclonal antibody targeting the high-affinity receptor binding site on human immunoglobulin lgE. Bound lgE is not available for basophil binding, degranulation is attenuated, and allergic symptoms are reduced. Omalizumab has been approved for the treatment of persistent allergic asthma in patients that are poorly controlled with inhaled corticosteroids $(136,137)$. Approximately $45 \%$ of patients with chronic urticaria have an IgG autoantibody directed to the alpha-subunit of the high-affinity IgE receptor (chronic autoimmune urticaria, CAU) leading to cutaneous mast cell and basophil activation. Treatment of allergic asthma with omalizumab produces rapid reduction in free $\lg \mathrm{E}$ levels and subsequent decrease in Fc epsilon RI expression on mast cells and basophils. If this occurs in CAU, cross-linking of lgE receptors by autoantibody would be less likely, reducing cell activation and urticaria/angioedema (138). Twelve patients with $\mathrm{CAU}$ were treated with placebo for 4 weeks, followed by omalizumab $(\geq 0.016 \mathrm{mg} / \mathrm{kg} /$ IU mL(-1) lgE per month) every 2 or 4 weeks for 16 weeks. Seven of twelve patients had complete symptom resolution, while one patient did not respond. Others showed improvement, but urticaria persisted (138).

Several authors report on good therapeutic response to omalizumab (139-146). Omalizumab is a steroid-sparing agent in autoimmune urticaria or CIU with angioedema (144). It has been used successfully in childhood urticaria (146). Successful treatment of cholinergic urticaria (147) and cold induced urticaria/anaphylaxis (148) with anti IgE therapy has also been published.

Recently, a few articles on allergic-like reactions to omalizumab have been published. A group of authors describe two patients. The in vitro and in vivo testing supported a conclusion that adverse reactions experienced by the two patients after more than a year of successful omalizumab therapy for asthma were most likely anaphylactoid in nature. Polysorbate, an excipient in omalizum$a b$, is known to cause similar reactivity to other medicines and is the most likely cause of these reactions $(149,150)$. 


\section{STANOZOLOL}

Stanozolol is an inexpensive anabolic steroid with a 30:1 anabolic:androgenic ratio. Only few papers have appeared on stanozolol in the management of chronic urticaria $(151,152)$. A group of authors report on treatment with $2 \mathrm{mg}$ stanozolol twice daily plus cetirizine $10 \mathrm{mg}$ daily compared with cetirizine $10 \mathrm{mg}$ daily, demonstrating that stanozolol is an effective and safe adjuvant therapy for the treatment of chronic refractory urticaria (152). The possible adverse effects include hirsutism, weight gain, menstrual irregularities or postmenopausal bleeding, acne, and mood changes (153-155).

\section{HYDROXYCHLOROQUINE}

There are only a few articles on the use of hydroxychloroquine in the management of chronic urticaria (156-158). In 2004, the impact of hydroxychloroquine (Plaquenil; Sanofi-Synthelabo) therapy on chronic urticaria was reported. Immunomodulation with hydroxychloroquine is safe and appears to offer some efficacy as an intervention in CIU.

\section{PUVA CHEMOTHERAPY AND UVB THERAPY}

There are little data to support the use of psoralen UVA (PUVA) photochemotherapy and UVB phototherapy for chronic urticaria (159-163). The efficacy of PUVA therapy in the management of chronic urticaria was assessed by a Canadian group of authors, and it was ranked as neutral or ineffective (164). A placebo controlled randomized trial was conducted on UVB phototherapy. Control group received antihistamine alone. Statistically significant differences were found and the authors concluded that narrow-band UVB could be an effective complementary treatment for patients with chronic urticaria (165).

\section{CONCLUSION}

Treatment of chronic urticaria can pose a major challenge to the physician. Many patients with chronic urticaria have at least partial response to antihistamines, but there are a proportion of patients that do not, thus requiring a more aggressive treatment with different types of immunomodulatory agents. Dermatologists must be knowledgeable about the implementation of correct treatment. There is a wide range of non-pharmacological and pharmacological options and there is no universal solution, therefore the most appropriate treatment should be tailored individually for each patient.

\section{References}

1. Grattan CE, Sabroe RA, Greaves MW. Chronic urticaria. J Am Acad Dermatol 2002;46:64557.

2. Zuberbier T, Maurer M. Urticaria: current opinions about etiology, diagnosis and therapy. Acta Derm Venereol 2007;87:196-205.

3. Novembre E, Cianferoni A, Mori F, Barni S, Calogero C, Bernardini R, et al. Urticaria and urticaria related skin condition/disease in children. Eur Ann Allergy Clin Immunol 2008;40:5-13.

4. Kozel MM, Sabroe RA. Chronic urticaria: aetiology, management and current and future treatment options. Drugs 2004;64:2515-36.

5. Negro-Alvarez JM, Miralles-Lopez JC. Chronic idiopathic urticaria treatment. Allergol Immunopathol (Madr) 2001;29:129-32.

6. Zuberbier T, Bindslev-Jensen C, Canonica W, Grattan CE, Greaves MW, Henz BM, et al. EEACI/GA²LEN/EDF guideline: definition, classification and diagnosis of urticaria. Allergy 2006;61:316-20.

7. Asero R, Tedeschi A. Emerging drugs for chronic urticaria. Expert Opin Emerg Drugs 2006;11:265-74.

8. Asero R, Riboldi P, Tedeschi A, Cugno M, Meroni P. Chronic urticaria: a disease between autoimmunity and coagulation. Autoimmun Rev 2007;7:71-6.

9. Zuberbier T, Bindslev-Jensen C, Canonica W, Grattan CE, Greaves MW, Henz BM, et al. EAACI/GA ${ }^{2}$ LEN/EDF guideline: management of urticaria. Allergy 2006;61:321-31.

10. Mastalerz L, Setkowicz M, SzczeklikA. Mechanism of chronic urticaria exacerbation by aspirin. Curr Allergy Asthma Rep 2005;5:27783.

11. Giavina-Bianchi $P$, Dente $M$, Giavina-Bianchi M, Mota AA, Kalil J. Codeine challenge in chronic urticaria patients. Allergol Immunopathol (Madr) 2007;35:280.

12. Zuberbier $T$, Chantraine-Hess $S$, Hartmann $K$, Czartnetzki MB. Pseudoallergen-free diet in the treatment of chronic urticaria - a prospective study. Acta Derm Venereol 1995;75:4847.

13. Zuberbier T. The role of allergens and pseudoallergens in urticaria. J Investig Dermatol Symp Proc 2001;6:132-4.

14. Moneret-Vautrin DA. Allergic and pseudo-al- 
lergic reactions to foods in chronic urticaria. Ann Dermatol Venereol 2003;130:35-42.

15. Mateus $C$. Treatment of chronic urticaria unresponsive to type 1 antihistamines in monotherapy. Ann Dermatol Venereol 2003;130:129-44.

16. Black AK, Greaves MW. Antihistamines in urticaria and angioedema. Clin Allergy Immunol 2002;17:249-86.

17. Fumagalli F, Baiardini I, Pasquali M, Compalati E, Guerra L, Massacane P, et al. Antihistamines: do they work? Further well controlled trials involving larger samples are needed. Allergy 2004;59:74-7.

18. Morgan MM, Khan DA, Nathan RA. Treatment for allergic rhinitis and chronic idiopathic urticaria: focus on oral antihistamines. Ann Pharmacother 2005;39:2056-64.

19. Monroe E. Review of $\mathrm{H} 1$ antihistamines in the treatment of chronic idiopathic urticaria. Cutis 2005;76:118-26.

20. Bleehen SS, Thomas SE, Greaves MW, Newton J, Kennedy CT, Hindley F, et al. Cimetidine and chlorpheniramine in the treatment of chronic idiopathic urticaria: a multi-centre randomized double-blind study. $\mathrm{Br} \mathrm{J}$ Dermatol 1987;117:81-8.

21. Yosipovitch G, Ansari N, Goon A, Chan YH, Goh CL. Clinical characteristics of pruritus in chronic idiopathic urticaria. $\mathrm{Br} \mathrm{J}$ Dermatol 2002;147:32-6.

22. Mann RD, Pearce GL, Dunn N, Shakir S. Sedation with "non-sedating" antihistamines: four prescription-event monitoring studies in general practice. BMJ 2000;320:1184-6.

23. Layton D, Wilton L, Boshier A, Cornelius V, Harris S, Shakir SA. Comparison of the risk of drowsiness and sedation between levocetirizine and desloratadine: a prescriptionevent monitoring study in England. Drug Saf 2006;29:897-909.

24. Kennard CD. Evaluation and treatment of urticaria. In: Charlesworth EN, ed. Immunology and Allergy Clinics of North America 1995;15:785-801.

25. Mann RD, Pearce GL, Dunn N, Shakir S. Sedation with "non-sedating" antihistamines: four prescription-event monitoring studies in general practice. BMJ 2000;320:1184-6.

26. de Abajo FJ, Rodríguez LA. Risk of ventricular arrhythmias associated with nonsedating antihistamine drugs. $\mathrm{Br} \mathrm{J}$ Clin Pharmacol 1999;47:307-13.

27. Viramontes-Madrid JL, Jerjes-Sánchez C, Pelaez-Ballestas I, Aguilar-Chiu A, Hernández-Garduño AG. Risk of drug interactions. Combinations of drugs associated with ventricular arrhythmias. Rev Invest Clin 2002;54:192-7.

28. Grob JJ, Auquier P, Dreyfus I, Ortonne JP. How to prescribe antihistamines for chronic idiopathic urticaria: desloratadine daily vs PRN and quality of life. Allergy 2009;64:60512.

29. Dhanya NB, Rai R, Srinivas CR. Histamine 2 blocker potentiates the effects of histamine 1 blocker in suppressing histamine-induced wheal. Indian J Dermatol Venereol Leprol 2008;74:475-7.

30. Devillier P, Roche N, Faisy C. Clinical pharmacokinetics and pharmacodynamics of desloratadine, fexofenadine and levocetirizine: a comparative review. Clin Pharmacokinet 2008;47:217-30.

31. Vena GA, Cassano N, Filieri M, Filotico R, D'Argento $\mathrm{V}$, Coviello $\mathrm{C}$. Fexofenadine in chronic idiopathic urticaria: a clinical and immunohistochemical evaluation. Int J Immunopathol Pharmacol 2002;15:217-24.

32. Kawashima M, Harada S, Tango T. Review of fexofenadine in the treatment of chronic idiopathic urticaria. Int J Dermatol 2002;41:7016.

33. Mason J, Reynolds R, Rao N. The systemic safety of fexofenadine $\mathrm{HCl}$. Clin Exp Allergy 1999;29:163-70.

34. Dhar S, Basu D, Mistri G, Hazra PK, Malakar $S$, Dutta AK. Evaluation of the efficacy and safety of fexofenadine in the management of chronic idiopathic urticaria: a prospective study with 512 patients. Indian J Dermatol Venereol Leprol 2002;68:73-6.

35. Pinto YM, van Gelder IC, Heeringa M, Crijns HJ. QT lengthening and life-threatening arrhythmias associated with fexofenadine. Lancet 1999;353:980.

36. Kaplan AP, Spector SL, Meeves S, Liao Y, Varghese ST, Georges G. Once-daily fexofenadine treatment for chronic idiopathic urticaria: a multicenter, randomized, doubleblind, placebo-controlled study. Ann Allergy Asthma Immunol 2005;94:662-9.

37. Mansfield LE. Fexofenadine in pediatrics: 
oral tablet and suspension formulations. Expert Opin Pharmacother 2008;9:329-37.

38. White M, Rothrock $S$, Meeves $S$, Liao $Y$, Georges G. Comparative effects of fexofenadine and montelukast on allergen-induced wheal and flare. Allergy Asthma Proc 2005;26:221-8.

39. Meltzer EO, Gillman SA. Efficacy of fexofenadine versus desloratadine in suppressing histamine-induced wheal and flare. Allergy Asthma Proc 2007;28:67-73.

40. Du Buske L. Desloratadine for chronic idiopathic urticaria: a review of clinical efficacy. Am J Clin Dermatol 2007;8:271-83.

41. Limon L, Kockler DR. Desloratadine: a nonsedating antihistamine. Ann Pharmacother 2003;37:237-46.

42. Murdoch D, Goa KL, Keam SJ. Desloratadine: an update of its efficacy in the management of allergic disorders. Drugs 2003;63:205177.

43. Ortonne JP, Grob JJ, Auquier P, Dreyfus I. Efficacy and safety of desloratadine in adults with chronic idiopathic urticaria: a randomized, double-blind, placebo-controlled, multicenter trial. Am J Clin Dermatol 2007;8:3742.

44. Ring J, Hein R, Gauger A. Desloratadine in the treatment of chronic idiopathic urticaria. Allergy 2001;56:28-32.

45. Bousquet J, Bindslev-Jensen C, Canonica G.W, Fokkens W, Kim H, Kowalski M, et al. The ARIA/EEACI criteria for antihistamines: an assessment of the efficacy, safety and pharmacology of desloratadine. Allergy 2004;77:4-16.

46. Lippert U, Moeller A, Welker P, Artuc M, Henz $B M$. Inhibition of cytokine secretion from human leukemic mast cells and basophils by $\mathrm{H} 1$ - and $\mathrm{H} 2$ receptor antagonist. Exp Dermatol 2000;9:118-24.

47. Schroeder JT, Schleimer RP, Lichtenstein LM, Kreutner W. Inhibition of cytokine generation and mediator release by human basophils treated with desloratadine. Clin Exp Allergy 2001;31:1369-77.

48. Agrawal DK. Pharmacology and clinical efficacy of desloratadine as an anti-allergic and anti-inflammatory drug. Expert Opin Investig Drugs 2001;10:547-60.

49. Grob JJ, Lachapelle JM. Non-sedating anti- histamines in the treatment of chronic idiopathic urticaria using patient-reported outcomes. Curr Med Res Opin 2008;24:2423-8.

50. Ring J, Hein R, Gauger A, Bronsky E, Miller B. Once-daily desloratadine improves the signs and symptoms of chronic idiopathic urticaria: a randomized, double-blind, placebo-controlled study. Int J Dermatol 2001;40:72-6.

51. Cassano N, Raho G, Filieri M, D'Argento $\mathrm{V}$, Amoruso A, Filotico R, et al. Influence of desloratadine on oxidative stress markers in patients with chronic idiopathic urticaria. Int J Dermatol 2006;45:394-6.

52. Bloom M, Staudinger $H$, Herron J. Safety of desloratadine syrup in children. Curr Med Res Opin 2004;20:1959-65.

53. Potter PC, Kapp A, Maurer M, Guillet G, Jian AM, Hauptmann $P$, et al. Comparison of the efficacy of levocetirizine $5 \mathrm{mg}$ and desloratadine $5 \mathrm{mg}$ in chronic idiopathic urticaria patients. Allergy 2009;64:596-604.

54. Frossard N, Strolin-Benedetti M, Purohit A, Pauli G. Inhibition of allergen-induced wheal and flare reactions by levocetirizine and desloratadine. Br J Clin Pharmacol 2008;65:1729.

55. Engin B, Ozdemir M. Prospective randomized non-blinded clinical trial on the use of dapsone plus antihistamine vs. antihistamine in patients with chronic idiopathic urticaria. $\mathrm{J}$ Eur Acad Dermatol Venereol 2008;22:481-6.

56. Khalaf AT, Liu XM, Sheng WX, Tan JQ, Abdalla AN. Efficacy and safety of desloratadine combined with dipyridamole in the treatment of chronic urticaria. J Eur Acad Dermatol Venereol 2008;22:487-92.

57. Di Lorenzo G, Pacor ML, Mansueto P, Esposito Pellitteri M, Lo Bianco C, Ditta V, et al. Randomized placebo-controlled trial comparing desloratadine and montelukast in monotherapy and desloratadine plus montelukast in combined therapy for chronic idiopathic urticaria. J Allergy Clin Immunol 2004;114:61925.

58. Ciprandi G, Tosca MA, Milanese M, Schenone G, Ricca V. Antihistamines added to an antileukotriene in treating seasonal allergic rhinitis: histamine and leukotriene antagonism. Eur Ann Allergy Clin Immunol 2004;36:67-70, 72.

59. Walsh GM. A review of the role of levocetirizine as an effective therapy for allergic dis- 
ease. Expert Opin Pharmacother 2008;9:85967.

60. Walsh GM. Levocetirizine: an update. Curr Med Chem 2006;13:2711-5.

61. Dubuske LM. Levocetirizine: the latest treatment option for allergic rhinitis and chronic idiopathic urticaria. Allergy Asthma Proc 2007;28:724-34.

62. Kapp A, Pichler WJ. Levocetirizine is an effective treatment in patients suffering from chronic idiopathic urticaria: a randomized, doubleblind, placebo-controlled, parallel, multicenter study. Int J Dermatol 2006;45:469-74.

63. Abramovits W, Gupta A. Xyzal (levocetirizine dihydrochloride). Skinmed 2008;7:84-5.

64. Hulhoven R, Rosillon D, Letiexhe M, Meeus MA, Daoust A, Stockis A. Levocetirizine does not prolong the QT/QTC interval in healthy subjects: results from a thorough QT study. Eur J Clin Pharmacol 2007;63:1011-7.

65. Caproni M, Volpi W, Giomi B, Torchia D, Del Bianco E, Fabbri P. Cellular adhesion molecules in chronic urticaria: modulation of serum levels occurs during levocetirizine treatment. Br J Dermatol 2006;155:1270-4.

66. Shih MY, Hsu JY, Weng YS, Fu LS. Influence of cetirizine and levocetirizine on two cytokines secretion in human airway epithelial cells. Allergy Asthma Proc 2008;29:480-5.

67. Arifhodzic N, Haines D, Novotney L. Levocetirizine modulates lymphocyte activation in patients with allergic rhinitis. J Pharmacol Sci 2008;108:149-56.

68. Hasala $H$, Janka-Junttila $M$, Moilanen $E$, Kankaanranta $\mathrm{H}$. Levocetirizine and cytokine production and apoptosis of human eosinophils. Allergy Asthma Proc 2007;28:582-91.

69. Cravo M, Gonçalo M, Figueiredo A. Fixed drug eruption to cetirizine with positive lesional patch tests to the three piperazine derivatives. Int J Dermatol 2007;46:760-2.

70. Sastre J. Ebastine in allergic rhinitis and chronic idiopathic urticaria. Allergy 2008;89:120.

71. Van Cauwenberge $P$, De Belder T, Sys L. A review of the second-generation antihistamine ebastine for the treatment of allergic disorders. Expert Opin Pharmacother 2004;5:1807-13.

72. Talavera Fabuel A, Arias Irigoyen J, Benavente Fernández M. Ebastine-induced hepato- toxicity. Gastroenterol Hepatol 2007;30:506.

73. Roberts DJ, Gispert J. The non-cardiac systemic side-effects of antihistamines: ebastine. Clin Exp Allergy 1999;29:151-5.

74. Cadahía A, Cardona V, Guilarte M, MuñozCano R. Safety of ebastine. Ann Allergy Asthma Immunol 2005;94:407.

75. Antonijoan R, García-Gea C, Puntes M, Pérez J, Esbrí R, Serra C, et al. Comparison of inhibition of cutaneous histamine reaction of ebastine fast-dissolving tablet $(20$ $\mathrm{mg}$ ) versus desloratadine capsule $(5 \mathrm{mg})$ : a randomized, double-blind, double-dummy, placebo-controlled, three-period crossover study in healthy, nonatopic adults. Clin Ther 2007;29:814-22.

76. Mullol J, Bousquet J, Bachert C, Canonica WG, Gimenez-Arnau A, Kowalski ML, et al. Rupatadine in allergic rhinitis and chronic urticaria. Allergy 2008;63:5-28.

77. Keam SJ, Plosker GL. Rupatadine: a review of its use in the management of allergic disorders. Drugs 2007;67:457-74.

78. Picado C. Rupatadine: pharmacological profile and its use in the treatment of allergic disorders. Expert Opin Pharmacother 2006;7:1989-2001.

79. Figueiredo A, Ribeiro CA, Gonçalo M, Almeida L, Poiares-Baptista A, Teixeira F. Mechanism of action of doxepin in the treatment of chronic urticaria. Fundam Clin Pharmacol 1990;4:147-58.

80. Greene SL, Reed CE, Schroeter AL. Doubleblind crossover study comparing doxepin with diphenhydramine for the treatment of chronic urticaria. J Am Acad Dermatol 1985;12:66975.

81. Riccioni G, Bucciarelli T, Mancini B, Di llio C, D'Orazio N. Antileukotriene drugs: clinical application, effectiveness and safety. Curr Med Chem 2007;14:1966-77.

82. Wan KS. Efficacy of leukotriene receptor antagonist with an anti-H1 receptor antagonist for treatment of chronic idiopathic urticaria. J Dermatol Treat 2008;11:1-4.

83. Erbagci $Z$. The leukotriene receptor antagonist montelukast in the treatment of chronic idiopathic urticaria: a single-blind, placebocontrolled, crossover clinical study. J Allergy Clin Immunol 2002;110:484-8. 
84. Nettis E, Colanardi MC, Paradiso MT, Ferrannini A. Desloratadine in combination with montelukast in the treatment of chronic urticaria: a randomized, double-blind, placebo-controlled study. Clin Exp Allergy 2004;34:1401-7.

85. McBayne TO, Siddall OM. Montelukast treatment of urticaria. Ann Pharmacother 2006;40:939-42.

86. Goel A, Prasad D. Oral montelukast in urticaria induced by nonsteroidal anti-inflammatory drugs. J Eur Acad Dermatol Venereol 2007;21:1275-6.

87. Pérez C, Sánchez-Borges M, Capriles E. Pretreatment with montelukast blocks NSAID-induced urticaria and angioedema. J Allergy Clin Immunol 2001;108:1060-1.

88. Asero R. Leukotriene receptor antagonists may prevent NSAID-induced exacerbations in patients with chronic urticaria. Ann Allergy Asthma Immunol 2000;85:156-7.

89. Zuberbier T, Ifflaender J, Semmler C, Czarnetzki BM. Acute urticaria - clinical aspects and therapeutical responsiveness. Acta Derm Venerol (Stockh) 1996;76:295-7.

90. Black AK, Greaves MW. Antihistamines in urticaria and angioedema. Clin Allergy Immunol 2002;17:249-86.

91. Mateus $\mathrm{C}$. Treatment of chronic idiopathic urticaria unresponsive to type 1 antihistamines in monotherapy. Ann Dermatol Venereol 2003;130:129-44.

92. Greaves M. Autoimmune urticaria. Clin Rev Allergy Immunol 2002;23:171-83.

93. Grattan CE, Francis DM, Slater NG, Barlow RJ, Greaves MW. Plasmapheresis for severe, unremitting, chronic urticaria. Lancet 1992;339:1078-80.

94. Jiang X, Lu M, Ying Y, Feng J, Ye Y. A case report of double-filtration plasmapheresis for the resolution of refractory chronic urticaria. Ther Apher Dial 2008;12:505-8.

95. Fromer L. Treatment options for the relief of chronic idiopathic urticaria symptoms. South Med J 2008;101:186-92.

96. Pereira C, Tavares B, Carrapatoso I, Loureiro G, Faria E, Machado D, et al. Low-dose intravenous gammaglobulin in the treatment of severe autoimmune urticaria. Eur Ann Allergy Clin Immunol 2007;39:237-42.

97. O'Donnell BF, Barr RM, Black AK, Francis DM, Kermani F, Niimi N, et al. Intravenous immunoglobulin in autoimmune chronic urticaria. Br J Dermatol 1998;138:101-6.

98. Kroiss M, Vogt T, Landthaler M, Stolz W. The effectiveness of low-dose intravenous immunoglobulin in chronic urticaria. Acta Derm Venereol 2000;80:225.

99. McGirt LY, Vasagar K, Gober LM, Saini SS, Beck LA. Successful treatment of recalcitrant chronic idiopathic urticaria with sulfasalazine. Arch Dermatol 2006;142:1337-42.

100. Jaffer AM. Sulfasalazine in the treatment of corticosteroid-dependent chronic idiopathic urticaria. J Allergy Clin Immunol 1991;88:964-5.

101. Hartmann K, Hani N, Hinrichs R, Hunzelmann N, Scharffetter-Kochanek K. Successful sulfasalazine treatment of severe chronic idiopathic urticaria associated with pressure urticaria. Acta Derm Venereol 2001;81:71.

102. Engler RJ, Squire E, Benson P. Chronic sulfasalazine therapy in the treatment of delayed pressure urticaria and angioedema. Ann Allergy Asthma Immunol 1995;74:155-9.

103. Gach JE, Sabroe RA, Greaves MW, Black AK. Methotrexate-responsive chronic idiopathic urticaria: a report of two cases. $\mathrm{Br} \mathrm{J}$ Dermatol 2001;145:340-3.

104. Montero Mora P, González Pérez C, Almeida Arvizu V, Matta Campos JJ. Autoimmune urticaria. Treatment with methotrexate. Rev Alerg Mex 2004;51:167-72.

105. Tedeschi A, Airaghi L, Lorini M, Asero R. Chronic urticaria: a role for newer immunomodulatory drugs? Am J Clin Dermatol 2003:4:297-305.

106. Lascari AD, Strano AJ, Johnson WW, Collins JG. Methotrexate-induced sudden fatal pulmonary reaction. Cancer 1977;40:1393-7.

107. likuni N, Iwami S, Kasai S, Tokuda H. Noncardiogenic pulmonary edema in low-dose oral methotrexate therapy. Intern Med 2004;43:846-51.

108. Calvo-Romero JM. Severe pancytopenia associated with low-dose methotrexate therapy for rheumatoid arthritis. Ann Pharmacother 2001;35:1575-7.

109. Shahar E, Bergman R, Guttman-Yassky E, Pollack S. Treatment of severe chronic idiopathic urticaria with oral mycophenolate mofetil in patients not responding to antihistamines and/or corticosteroids. Int J Dermatol 2006;45:1224-7. 
110. Geevasinga N, Wallman L, Katelaris CH. Mycophenolate mofetil; a review of indications and use in a large tertiary hospital. Iran J Allergy Asthma Immunol 2005;4:159-66.

111. Bernstein JA, Garramone SM, Lower EG. Successful treatment of autoimmune chronic idiopathic urticaria with intravenous cyclophosphamide. Ann Allergy Asthma Immunol 2002;89:212-4.

112. Kumar R, Verma KK, Pasricha JS. Efficacy of $\mathrm{H}$, antihistamine, corticosteroids and cyclophosphamide in the treatment of chronic dermographic urticaria. Indian J Dermatol Venereol Leprol 2002;68:88-91.

113. Asero R. Oral cyclophosphamide in a case of cyclosporin and steroid-resistant chronic urticaria showing autoreactivity on autologous serum skin testing. Clin Exp Dermatol 2005;30:582-3.

114. Peterlana D, Puccetti A, Tinazzi E, Simeoni S, Lunardi C. Schnitzler's syndrome treated successfully with intravenous pulse cyclophosphamide. Scand J Rheumatol 2005;34:32830.

115. Barlow RJ, Black AK, Greaves MW. Treatment of severe chronic urticaria with cyclosporine A. Eur J Dermatol 1993;3:273-25.

116. Toubi E, Blant A, Kessel A, Golan TD. Lowdose cyclosporin $A$ in the treatment of severe chronic idiopathic urticaria. Allergy 1997;52:312-6.

117. Grattan CE, O'Donell BF, Francis DM, Niimi N, Bralow RJ, Seed PT, et al. Randomized double-blind study of cyclosporine in chronic "idiopathic" urticaria. Br J Dermatol 2000;143:365-72.

118. Vena GA, Cassano N, Colombo D, Peruzzi E, Pigatto P; NEO-I-30 Study Group. Cyclosporine in chronic idiopathic urticaria: a doubleblind, randomized, placebo-controlled trial. J Am Acad Dermatol 2006;55:705-9.

119. Lipozenčić J, Ljubojević S. Cyclosporine in chronic idiopathic urticaria. Acta Dermatovenereol Croat 2007;15:50.

120. Di Gioacchino M, Di Stefano F, Cavallucci E, Verna N, Ramondo S, Paolini F, et al. Treatment of chronic idiopathic urticaria and positive autologous serum skin test with cyclosporine: clinical and immunological evaluation. Allergy Asthma Proc 2003;24:285-90.

121. Toubi E, Bamberger E, Kessel A. Prolonged cyclosporin-A treatment for severe chronic urticaria. Allergy 2003;58:535-6

122. Serhat Inaloz H, Ozturk S, Akcali C, Kirtak N, Tarakcioglu M. Low-dose and short-term cyclosporine treatment in patients with chronic idiopathic urticaria: a clinical and immunological evaluation. J Dermatol 2008;35:276-82.

123. Madan V, Griffiths CE. Systemic cyclosporin and tacrolimus in dermatology. Dermatol Ther 2007;20:239-50.

124. Marsland AM, Soundararajan S, Joseph K, Kaplan AP. Effects of calcineurin inhibitors on an in vitro assay for chronic urticaria. Clin Exp Allergy 2005;35:554-9.

125. Leyral C, Beylot-Barry M, Vergier B, Begueret $\mathrm{H}$, Dromer C, Doutre MS, et al. Cyclosporineinduced follicular eruption. Ann Dermatol Venereol 2008;135:58-62.

126. Boschnakow A, May T, Assaf C, Tebbe B, Zouboloullis ChC. Cyclosporin A-induced sebaceous gland hyperplasia. Br J Dermatol 2003;149:198-200.

127. Engel F, Ellero B, Woehl-Jaegle ML, Cribier $B$. Diffuse sebaceous hyperplasia of the face induced by cyclosporine. Ann Dermatol Venereol 2005;132:342-5.

128. Ramalho VL, Ramalho HJ, Cipullo JP, Burdmann EA. Cyclosporine A-induced gingival hyperplasia. Rev Assoc Med Bras 2003;49:2103.

129. Braun R, Arechalde A, French LE. Reversible ascending motor neuropathy as a side effect of systemic treatment with cyclosporine for nodular prurigo. Dermatology 1999;199:3723.

130. Mihatsch MJ, Kyo M, Morozumi K, Yamaguchi Y, Nickeleit V, Ryffel M. The side-effects of cyclosporine-A and tacrolimus. Clin Nephrol 1998;49:356-63.

131. Vigil SV, de Liz R, Medeiros YS, Froede TS. Efficacy of tacrolimus in inhibiting inflammation caused by carrageenan in a murine model of air pouch. Transpl Immunol 2008;19:259.

132. Kessel A, Bamberger E, Toubi E. Tacrolimus in the treatment of severe chronic idiopathic urticaria: an open-label prospective study. J Am Acad Dermatol 2005;52:145-8.

133. Stanaland BE. Treatment of patients with chronic idiopathic urticaria. Clin Rev Allergy Immunol 2002;23:233-41.

134. Cezario ES, Cota LO, Ferreira SD, Siqueira 
FM, Soares RV, Zenobio EG, et al. Gingival overgrowth in renal transplant subjects medicated with tacrolimus in the absence of calcium channel blockers. Transplantation 2008;27:232-6.

135. First MR. First clinical experience with the new once-daily formulation of tacrolimus. Ther Drug Monit 2008;30:159-66.

136. Mankad VS, Burks AW. Omalizumab: other indications and unanswered questions. Clin Rev Allergy Immunol 2005;29:17-30.

137. Belliveau PP. Omalizumab: a monoclonal anti-IgE antibody. MedGenMed 2005;27:727.

138. Kaplan AP, Joseph K, Maykut RJ, Geba GP, Zeldin RK. Treatment of chronic autoimmune urticaria with omalizumab. J Allergy Clin Immunol 2008;122:569-73.

139. Spector SL, Tan RA. Therapeutic alternatives for chronic urticaria: additional reports on omalizumab. Ann Allergy Asthma Immunol 2008; 101:647.

140. Callejas-Rubio JL, Sánchez-Cano D, Lara MA, Ortego-Centeno H. Omalizumab as a therapeutic alternative for chronic urticaria. Ann Allergy Asthma Immunol 2008;101:556.

141. Spector SL, Tan RA. Omalizumab also successful in chronic urticaria. J Allergy Clin Immunol 2008;121:784.

142. Godse KV. Omalizumab in severe chronic urticaria. Indian J Dermatol Venereol Leprol 2008;74:157-8.

143. Sheikh J. Effect of omalizumab on patients with chronic urticaria: issues with the determination of autoimmune urticaria. Ann Allergy Asthma Immunol 2008;100:88-9.

144. Dreyfus DH. Observations on the mechanism of omalizumab as a steroid-sparing agent in autoimmune or chronic idiopathic urticaria and angioedema. Ann Allergy Asthma Immunol 2008;100:624-5.

145. Graves JE, Nunley K, Heffernan MP. Off-label uses of biologics in dermatology: rituximab, omalizumab, infliximab, etanercept, adalimumab, efalizumab and alefacept. J Am Acad Dermatol 2007;56:55-79.

146. Bailey E, Shaker M. An update on childhood urticaria and angioedema. Curr Opin Pediatr 2008;20:425-30.

147. Metz M, Bergmann P, Zuberbier T, Maurer M. Successful treatment of cholinergic urticaria with anti-immunoglobulin E therapy. Allergy 2008;63:247-9.

148. Boyce JA. Successful treatment of cold-induced urticaria/anaphylaxis with anti-lgE. J Allergy Clin Immunol 2006;117:1415-8.

149. Dreyfus DH, Randolph CC. Characterization of an anaphylactoid reaction to omalizumab. Ann Allergy Asthma Immunol 2006;96:624-7.

150. Price KS, Hamilton RG. Anaphylactoid reactions in two patients after omalizumab administration after successful long-term therapy. Allergy Asthma Proc 2007;28:313-9.

151. Brestel EP, Thrush LB. The treatment of glucocorticosteroid-dependent chronic urticaria with stanozolol. J Allergy Clin Immunol 1988;82:265-9.

152. Parsad D, Pandhi R, Juneja A. Stanozolol in chronic urticaria: a double blind, placebo controlled trial. J Dermatol 2001;28:299-302.

153. Sloane DE, Lee CW, Sheffer AL. Hereditary angioedema: safety of long-term stanozolol therapy. J Allergy Clin Immunol 2007;120:654-8.

154. Sheffer AL, Fearon DT, Austen KF. Clinical and biochemical effects of stanozolol therapy for hereditary angioedema. J Allergy Clin Immunol 1981;68:181-7.

155. Lipozenčić J, Wolf R. Life-threatening severe allergic reactions: urticaria, angioedema, and anaphylaxis. Clin Dermatol 2005;23:193205.

156. Komarow HD, Metcalfe DD. Office-based management of urticaria. Am $\mathrm{J}$ Med 2008;121:379-84.

157. Hachulla E. Systemic urticarias. Ann Dermatol Venereol 2003;130:53-68.

158. Reeves GE, Boyle MJ, Bonfield J, Dobson P, Loewenthal M. Impact of hydroxychloroquine therapy on chronic urticaria: chronic autoimmune urticaria study and evaluation. Intern Med J 2004;34:182-6.

159. Hönigsmann H. Mechanisms of phototherapy and photochemotherapy for photodermatoses. Dermatol Ther 2003;16:23-7.

160. Grattan C, Powell S, Humphreys F. Management and diagnostic guidelines for urticaria and angioedema. $\mathrm{Br} J$ Dermatol 2001;144:708-14.

161. Cisło M, Szybejko-Machaj G, Maj J. Usefulness of photochemotherapy in allergic diseases of the skin. Przegl Dermatol 1989;76:14651. 
162. Olafsson JH, Larkö O, Roupe G, Granerus G, Bengtsson U. Treatment of chronic urticaria with PUVA or UVA plus placebo: a doubleblind study. Arch Dermatol Res 1986;278:22831.

163. Midelfart K, Moseng D, Kavli G, Stenvold SE, Volden G. A case of chronic urticaria and vitiligo, associated with thyroiditis, treated with PUVA. Dermatologica 1983;167:39-4.
164. Sharma JK, Miller R, Murray S. Chronic urticaria: a Canadian perspective on patterns and practical management strategies. J Cutan Med Surg 2000;4:89-93.

165. Engin B, Ozdemir M, Balevi A, Mevlitoğlu I. Treatment of chronic urticaria with narrowband ultraviolet B phototherapy: a randomized controlled trial. Acta Derm Venereol 2008;88:247-51.

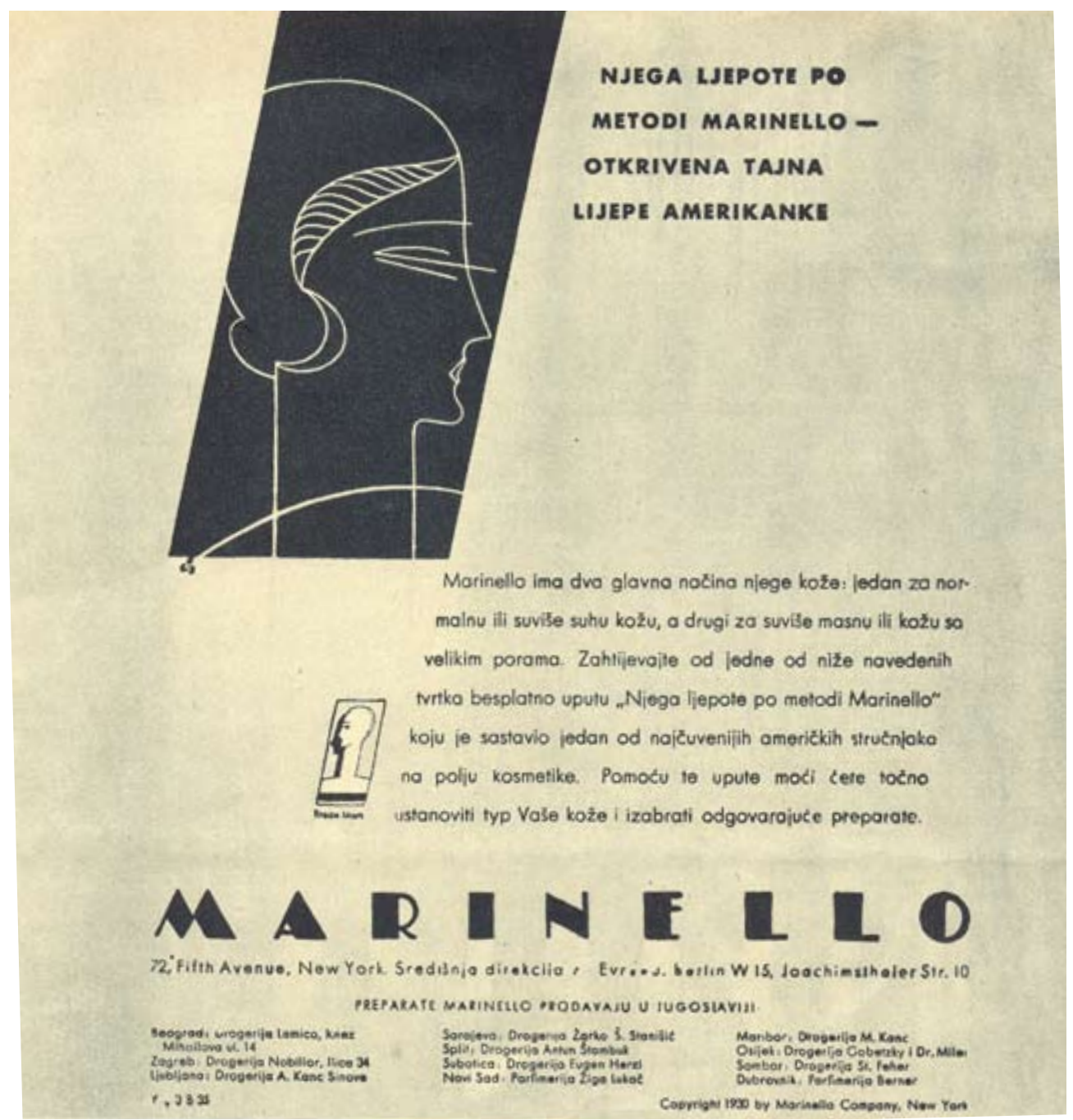

Beauty care according Marinello method - Secret of beautiful American women is discovered; year 1930.

(From the collectiion of Mr. Zlatko Puntijar) 